\title{
1 - Ações para a segurança do paciente
}

\author{
Celsa Raquel Villaverde Melgarejo \\ Patricia de Carvalho Mastroianni \\ Fabiana Rossi Varallo
}

\section{SciELO Books / SciELO Livros / SciELO Libros}

MELGAREJO, C. R. V., MASTROIANNI, P. C., and VARALLO, F. R. Ações para a segurança do paciente. In.: Promoção da cultura de notificação de incidentes em saúde [online]. São Paulo: Editora UNESP, 2019,pp. 13-17. ISBN: 978-85-9546-337-0. https://doi.org/10.7476/9788595463370.0003.

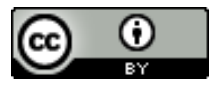

All the contents of this work, except where otherwise noted, is licensed under a Creative Commons Attribution 4.0 International license.

Todo o conteúdo deste trabalho, exceto quando houver ressalva, é publicado sob a licença Creative Commons Atribição 4.0.

Todo el contenido de esta obra, excepto donde se indique lo contrario, está bajo licencia de la licencia Creative Commons Reconocimento 4.0. 


\section{1 \\ Ações PARA A SEGURANÇA do PACIENTE}

Em razão das falhas de ações e de processos relacionados à prestação de cuidados à saúde afetarem um em cada dez pacientes em todo o mundo (WHO, 2009b), a Aliança Mundial para a Segurança do Paciente (Word Alliance for Patient Safety - WHO) vem contribuindo de forma ativa desde o ano de sua criação, 2004, para a solução e redução de erros e/ou incidentes na assistência à saúde (WHO, 2004).

Dentre as soluções previstas em 2005 pela Organização Mundial da Saúde (OMS) e pela The Joint Commission (TJC), como centro colaborador para a Segurança do Paciente, foi lançado em maio de 2007 nove metas e soluções para a prevenção de incidentes no cuidado à saúde:

1. identificar corretamente de pacientes;

2. gerenciar medicamentos com grafia e/ou aparência semelhantes;

3. realizar procedimento correto no local correto;

4. promover a comunicação efetiva e adequada na transferência de pacientes;

5. realizar procedimento certo na parte certa do corpo;

6. realizar conciliação medicamentosa e evitar erros de medicação; 
7. evitar conexão errada de dispositivos invasivos, como cateteres e tubo endotraqueal;

8. utilizar uma única vez dispositivos para injeções;

9. realizar correta higienização das mãos, para prevenção de infecções associadas aos cuidados em saúde. (WHO, 2005b; 2008b)

Os objetivos do programa da OMS, dentre tantos outros, era organizar os conceitos e as definições sobre a segurança do paciente, além de propor medidas para minimizar os riscos inerentes aos incidentes da saúde (WHO, 2008b).

A Aliança Mundial para Segurança do Paciente tem como foco a elaboração de "Desafios Globais" como forma de campanhas para promover a segurança por meio do desenvolvimento de taxonomia padronizada, da disponibilização de ferramentas para elaboração de normas e avaliações de pesquisas, de orientações de boas práticas assistenciais e no cuidado à saúde. Sendo assim, no ano de 2005, a OMS lançou seu primeiro Desafio Global para a Segurança do Paciente cujo tema foi "Clean Care is Safe Care?" e teve como foco as Infecções Relacionadas à Assistência à Saúde (Iras) (WHO, 2005a). Essa publicação abordou padrões simples e claros no que tange à higienização das mãos; procedimentos clínicos seguros; segurança com o sangue e com os hemoderivados; administração segura de injetáveis e de imunobiológicos; segurança da água e manejo de resíduos como medidas necessárias para prevenção e redução de eventos associados às infecções. Com isso, a OMS elaborou o primeiro manual para higienização das mãos na assistência à saúde (WHO, 2005a; 2008b).

O Segundo Desafio Global para a Segurança do Paciente ocorreu nos anos de 2007 e 2008 com o tema "Cirurgia Segura Salva Vidas", que teve como meta central a melhoria no cuidado cirúrgico por meio de práticas seguras, mediante um conjunto de medidas que pudesse ser adotado em diversos países. Fazem parte dessas práticas ações como a prevenção de infecções do sítio cirúrgico, anestesia segura, equipes cirúrgicas seguras e indicadores da assistência cirúrgica. A campanha desenvolvida a partir da conjuntura dessas ações denominou-se "Cirurgias Seguras Salvam Vidas" e foi posta em 
prática primeiramente nos países-membros da OMS (Weerakkody et al., 2013; WHO, 2008a, 2016).

Recentemente, em março de 2017, foi lançado o Terceiro Desafio Global, cujo tema "Medicação sem danos" visa reduzir pela metade os danos graves e evitáveis associados a erros de medicação nos próximos cinco anos, além de preveni-los. Problemas relacionados ao uso de medicamentos estão entre as principais causas de incidentes no mundo, assim como um dos mais frequentes em serviços de saúde.

Destacam-se também os custos adicionais de tratamentos em decorrência de danos causados pelo uso de medicamentos. Por isso a importância da prática do uso racional de medicamentos (URM), que é garantir ao paciente o recebimento da medicação apropriada à sua condição clínica, nas doses adequadas, respeitando a individualidade durante o tempo necessário e ao menor custo possível (Feldman et al. 2017; OMS, 2002)1993.

Com base nas dez causas de mortes mais frequentes apontadas pela OMS em 2014, a Organização Pan-Americana de Saúde (Opas) e a OMS/Brasil lançaram em novembro de 2017 a versão completa da série "Uso racional de medicamentos: fundamentação em condutas terapêuticas e nos macroprocessos da assistência farmacêutica”, cujo objetivo é a orientação e difusão de informação confiável, com linguagem acessível e de elevada evidência científica, designados a todos os profissionais da saúde.

Os assuntos que compõe a publicação estão divididos em fascículos com abordagem de diferentes temas, e têm livre acesso pela página Web da Opas/OMS. Alguns dos conteúdos abordados são: tratamento da dor lombar, prevenção primária de cardiopatia isquêmica, novas opções para tratamento da artrite reumatoide, uso de insulina no tratamento de diabetes mellitus, tratamento medicamentoso em idosos com depressão, uso do misoprostol em hemorragias pós-parto e contracepções na adolescência, além de temas referentes ao uso racional de medicamentos e do ciclo da assistência farmacêutica, como dispensação, distribuição, armazenamento, prescrição (Paho, 2017). Almeja-se que, a partir desse documento, seja possível diminuir a incidência de iatrogenias e adoção 
de condutas terapêuticas que beneficiem a população a ser tratada, considerando seus aspectos socioeconômicos e culturais.

\section{A segurança do paciente no Brasil}

No Brasil, os temas dos Desafios Globais vêm sendo trabalhados por meio de campanhas promovidas pela Agência Nacional de Vigilância Sanitária (Anvisa) e pelo Ministério da Saúde (MS) desde 2007. A partir de 2012, deu-se início a um estudo de investigação para conhecer a frequência e a evitabilidade dos incidentes nos países da América (Aranaz-Andres et al., 2011), e a partir da implantação do Programa Nacional de Segurança do Paciente (PNSP), por meio da portaria MS/GM n. 529, de $1^{\circ}$ de abril em 2013, têm sido trabalhada a segurança do paciente no Brasil, com o objetivo de contribuir para a qualificação do cuidado e da saúde em todo o país. Isso é realizado pelo gerenciamento de seis indicadores e protocolos: prevenção de quedas; identificação correta do paciente; cirurgia segura; práticas de higienização das mãos em serviços de saúde; prevenção de lesão por pressão; erros de medicação com enfoque para a segurança nas prescrições e uso de medicamentos (Brasil, 2013a).

Os protocolos, estabelecidos e recomendados pela Portaria n. 529, constituem a base dos componentes obrigatórios dos planos de segurança do paciente de acordo com a RDC n. 36, de 25 de julho de 2013. Essa resolução trata da criação dos Núcleos de Segurança do Paciente (NSP) nos serviços de saúde e define seus princípios e diretrizes, aborda suas competências e traça vários planos referentes à segurança do paciente, incluindo a vigilância e o monitoramento das notificações de incidentes (Brasil, 2013b).

Além do que já está previsto na legislação, cabe ressaltar outros incentivos à segurança do paciente no país, dentre eles a Rede Sentinela, criada em meados de 2001 e composta por hospitais escolas que monitoram a qualidade e o perfil de segurança dos medicamentos utilizados em ambiente hospitalar por meio das notificações de incidentes; Rede Brasileira de Enfermagem e Segurança do Paciente 
(Rebraensp), criada em 2008 com iniciativa da Opas, cuja meta é difundir e sedimentar a cultura de segurança do paciente nas diversas instituições de saúde, universidades, organizações não governamentais e comunidades no geral, além de entidades multiprofissionais, como o Institute for Safe Medication Practice (ISMP), dos Estados Unidos, e o Instituto Brasileiro para Segurança do Paciente (IBSP), que têm promovido eventos nacionais sobre o tema. 